\title{
Health shocks and child time allocation decisions by households: evidence from Ethiopia
}

Yonatan Dinku, David Fielding ${ }^{*}$ and Murat Genç

\author{
* Correspondence: \\ david.fielding@otago.ac.nz \\ Department of Economics, \\ University of Otago, Dunedin 9054, \\ New Zealand
}

\begin{abstract}
Little is currently known about the effects of shocks to parental health on the allocation of children's time between alternative activities. Using longitudinal data from the Ethiopian Young Lives surveys of 2006 and 2009, we analyse the effect of health shocks on the amount of children's time spent in work, leisure and education. One key contribution of the paper is that we distinguish between child labour as defined by organisations such as the International Labour Organisation and other types of child work, such as light domestic chores. We find that paternal illness increases the time spent in income-generating work but maternal illness increases the time spent in domestic work. Moreover, maternal illness has a relatively large effect on daughters while paternal illness has a relatively large effect on sons. Overall, parental illness leads to large and significant increases in the amount of child labour.

JEL Classification: D13, 112, 121, O15

Keywords: Parental illness, Child labour, Ethiopia
\end{abstract}

\section{Introduction}

In developing countries, the opportunity cost of children's time is likely to be higher when the parents' income-generating capacity is lower, so negative household income shocks will reduce children's education and play time and increase their work time (Basu and Van 1998). Evidence for such an effect has been found in studies of agricultural productivity shocks (Beegle et al. 2006; Colmer 2013; Guarcello et al. 2008) and employment shocks (Duryea et al. 2007; Guarcello et al. 2010). ${ }^{1}$ Fallon and Tzannatos (1998) and Udry (2006) argue that child labour is a consequence of chronic poverty, and there is some evidence for such a link from cross-country studies (Edmonds and Pavcnik 2005), country-specific studies (Jensen and Nielsen 1997; Edmonds 2005), and cash-transfer experiments (Edmonds 2006; Edmonds and Schady 2009; Bourguignon et al. 2003).

This paper focuses on the effects on children's time allocation of shocks to parental health. Parental health shocks could have an especially large effect on children's time, because a child is required not only to provide a substitute for adult labour but also to care for the parent. The child's education could be adversely affected because the household can no longer afford to pay for it, or because the child has no time to study (Haile and Haile 2012; Rosati and Rossi 2001; Rosenzweig and Evenson 1977; Udry

(c) The Author(s). 2018 Open Access This article is distributed under the terms of the Creative Commons Attribution 4.0 International License (http://creativecommons.org/licenses/by/4.0/), which permits unrestricted use, distribution, and reproduction in any medium, provided you give appropriate credit to the original author(s) and the source, provide a link to the Creative Commons license, and indicate if changes were made. 
2006), or because the child is fatigued by strenuous or hazardous employment (Duryea et al. 2007; Heady 2003). There is already a small literature on the links between parental illness, child labour and education, but only two papers (Dillon 2012; Alam 2015) which estimate the impact of adult health shocks on the allocation of children's time across a range of activities, rather than just on time spent in school.

Our analysis embodies a number of distinctive features. Firstly, we distinguish between different types of child work using two alternative types of disaggregation. We distinguish between different kinds of activity (education, play, domestic chores inside the home and work outside the home), and we also distinguish between (i) time spent on innocuous household chores or light work outside the home and (ii) child labour as defined by organisations such as the International Labour Organisation (ILO) and the United Nations Children's Emergency Fund (UNICEF). Depending on their age and the type of task they perform, children might benefit from light work: they might acquire skills useful in future life or earn income that can help to finance their own education and health (Cigno and Rosati 2002; Moehling 2005). We believe that this distinction enhances the relevance of our results to policymakers, who may be concerned primarily with child labour as defined by the ILO and UNICEF-i.e. work that is harmful to the child's wellbeing and personal development. Secondly, we estimate the effects of parental illness using a panel dataset that allows us to control for unobserved heterogeneity at the household level. Such heterogeneity could arise if, for example, there are some parents who put relatively little value on human capital and so invest in neither their own health nor their children's education. Thirdly, while we do control for shocks to the health of adults in the household other than the mother and father, our main focus is on parental health shocks, and on asymmetries in (i) the effect of maternal health shocks on girls and boys and (ii) the effect of paternal health shocks on girls and boys.

Our study uses data for two cohorts of children in the Ethiopian Young Lives survey. One of the key original contributions of this paper is that we estimate the impact of parental health shocks on the allocation on children's time in a way that allows for a distinction between child work and child labour. This distinction is based on the definition of child labour developed by UNICEF (United Nations 1989), which is consistent with the guidelines in the ILO's Minimum Age Convention (ILO 1973) and the resolutions of the 18th International Conference of Labour Statisticians (ILO 2008). This definition takes into account work intensity and the child's age. We also distinguish between the effects of paternal and maternal illness, and between the effects on sons and the effects on daughters. Our results are based on fixed-effects estimates that allow for unobserved heterogeneity.

We find that parental illness has a large and statistically significant effect on the allocation of children's time, but that there are asymmetries between maternal and paternal illness. Paternal illness reduces time spent in school while increasing time spent in income-generating work, but maternal illness reduces time spent in play and incomegenerating work while increasing time spent in domestic work. Moreover, maternal illness has a larger impact on daughters while paternal illness has a larger impact on sons. In this way, the effects of parental illness appear to reflect traditional gender roles within the household. There is also some heterogeneity in the effects of parental illness on the prevalence of child labour. Overall, serious maternal illness is associated with a ten percentage point increase in prevalence while serious paternal illness has a smaller 
effect. However, maternal illness has a relatively large effect on prevalence among girls and paternal illness a relatively large effect on prevalence among boys.

\section{Data and descriptive statistics}

Our data are taken from the Ethiopian Young Lives surveys of 2006 and 2009 (www.younglives.org.uk/content/ethiopia). ${ }^{2}$ As with Young Lives surveys in other countries, the Ethiopian sample comprises two cohorts of children in a stratified sample of villages: one cohort was aged $0.5-1.5$ years in 2002 while the other was aged 7.5-8.5 years in 2002. It is the existence of two cohorts that provides much of the variation in the child age variable in our sample. Before attrition, the younger cohort comprises 2000 children and the older cohort 1000 children. $^{3}$ After attrition due to mortality and other factors, ${ }^{4}$ and after excluding children aged under five or living in single-parent households at the time of the survey, we have sample sizes of 1299 and 970 respectively. However, only one child is sampled in each household, so there is no distinction between child fixed effects and household fixed effects.

Table 1 shows summary statistics for children's daily time allocation between play, schooling (including homework), domestic chores and income-generating work, and Figs. 1, 2, 3 and 4 contain the corresponding histograms. Income-generating work includes activities such as street vending, work on the farm or serving in the family store. Domestic chores include activities such as washing, cooking, cleaning and caregiving; these definitions are consistent with those of the United Nations (2009). The table shows a marked upward trend in schooling time and downward trend in play time; this corresponds to an increase in the school enrolment rate from 56\% in 2006 to $85 \%$ in $2009 .^{5}$ There is also a substantial percentage increase in income-generating work time. On average, income-generating work only makes up a small proportion of children's time, but the low mean is accompanied by a high standard deviation, so there are some children who are spending a substantial proportion of their time in income-generating work. Note that this work is not motivated by a need to pay for schooling, because Ethiopian public schools do not charge fees. The table also shows some gender asymmetries. Although boys and girls spend roughly the same amount of time on average in play, schooling and work, the girls' work time is much more dominated by domestic chores while boys spend a substantial amount of time in income-generating work. This may reflect cultural norms relating to gender roles: for example, boys do not normally cook, and it is sometimes unacceptable for a girl to leave home unaccompanied. The figures show that the distributions of all four activities are left-skewed, but the skewness is more marked for schooling and income-generating work, with many children either not attending school or not going out to work. Finally, the table includes mean values for each activity disaggregated by the health status of the parents. It can be seen that parental illness is generally associated with an increase time spent in domestic chores and income-generating work and a decrease in time spent in play and schooling. Note, however, that these are unconditional associations which do not necessarily correspond to a causal effect.

Neither of the work categories in Table 1 corresponds to standard definitions of child labour. In this paper, we will analyse both the work categories in Table 1 and child labour as defined by UNICEF. For children aged 5-11 years, child labour is 
Table 1 Descriptive statistics

\begin{tabular}{|c|c|c|c|c|c|}
\hline \multicolumn{6}{|l|}{ A. Allocation of children's time } \\
\hline 2006 Survey Round & Play & Schooling & Domestic chores & $\begin{array}{l}\text { Income-generating } \\
\text { work }\end{array}$ & Sample size \\
\hline Total mean hours & 6.4 & 4.4 & 2.8 & 1.0 & 2269 \\
\hline Std. dev. & 4.1 & 4.0 & 1.9 & 1.8 & \\
\hline Median & 5.0 & 6.0 & 3.0 & 0.0 & \\
\hline Prevalence of non-zero hours & $100 \%$ & $57 \%$ & $90 \%$ & $30 \%$ & \\
\hline Mean hours when no parent is ill & 6.8 & 4.5 & 2.4 & 0.9 & \\
\hline Mean hours when mother is ill & 5.4 & 4.6 & 3.9 & 0.7 & \\
\hline Mean hours when father is ill & 6.5 & 3.9 & 2.6 & 1.8 & \\
\hline Mean hours when both parents ill & 5.8 & 3.5 & 3.9 & 1.4 & \\
\hline Boys mean hours & 6.6 & 4.3 & 2.5 & 1.3 & 1204 \\
\hline Prevalence of non-zero hours & $100 \%$ & $56 \%$ & $90 \%$ & $38 \%$ & \\
\hline Girls mean hours & 6.2 & 4.5 & 3.1 & 0.6 & 1065 \\
\hline Prevalence of non-zero hours & $100 \%$ & $58 \%$ & $91 \%$ & $23 \%$ & \\
\hline 2009 Survey Round & Play & Schooling & Domestic chores & $\begin{array}{l}\text { Income-generating } \\
\text { work }\end{array}$ & Sample size \\
\hline Total mean hours & 3.8 & 6.6 & 3.0 & 1.6 & 2269 \\
\hline Std. dev. & 2.2 & 3.0 & 1.9 & 2.4 & \\
\hline Median & 3.0 & 7.0 & 3.0 & 0.0 & \\
\hline Prevalence of non-zero hours & $100 \%$ & $87 \%$ & $96 \%$ & $43 \%$ & \\
\hline Mean hours when no parent is ill & 3.9 & 7.2 & 2.7 & 1.4 & \\
\hline Mean hours when mother is ill & 3.3 & 6.1 & 4.1 & 1.4 & \\
\hline Mean hours when father is ill & 4.1 & 5.3 & 3.1 & 2.5 & \\
\hline Mean hours when both parents ill & 3.7 & 5.6 & 3.7 & 2.0 & \\
\hline Boys mean hours & 3.9 & 6.5 & 2.9 & 2.4 & 1204 \\
\hline Prevalence of non-zero hours & $100 \%$ & $86 \%$ & $93 \%$ & $57 \%$ & \\
\hline Girls mean hours & 3.6 & 6.7 & 3.8 & 0.8 & 1065 \\
\hline Prevalence of non-zero hours & $100 \%$ & $88 \%$ & $99 \%$ & $27 \%$ & \\
\hline \multicolumn{6}{|l|}{ B. Incidence of household shocks } \\
\hline 2006 & 2009 & & & 2006 & 2009 \\
\hline Maternal illness & $35 \%$ & \multicolumn{2}{|c|}{ Illness of another person } & $25 \%$ & $29 \%$ \\
\hline Paternal illness & $21 \%$ & \multicolumn{2}{|c|}{ Loss of paid employment } & $10 \%$ & $11 \%$ \\
\hline Crop failure & $26 \%$ & \multicolumn{2}{|c|}{ Forced eviction } & $3 \%$ & $4 \%$ \\
\hline Theft & $10 \%$ & Death of li & vestock & $25 \%$ & $30 \%$ \\
\hline
\end{tabular}

defined as domestic chores in excess of $28 \mathrm{~h}$ per week or any income-generating work; for children aged 12-14 years, child labour is defined as domestic chores in excess of $28 \mathrm{~h}$ per week or income-generating work is excess of $14 \mathrm{~h}$ per week (there are no children in our sample over the age of 14). Using these definitions, the incidence of child labour across the two rounds of the survey is $54 \%$ for both age groups. The under-11s account for two thirds of the sample and therefore two thirds of the cases of child labour.

Table 1 also reports the proportion of children whose mothers or fathers report having been ill in the 3 years prior to the survey. ${ }^{6}$ The incidence of maternal illness is higher than the incidence of paternal illness; moreover, the incidence of paternal illness 


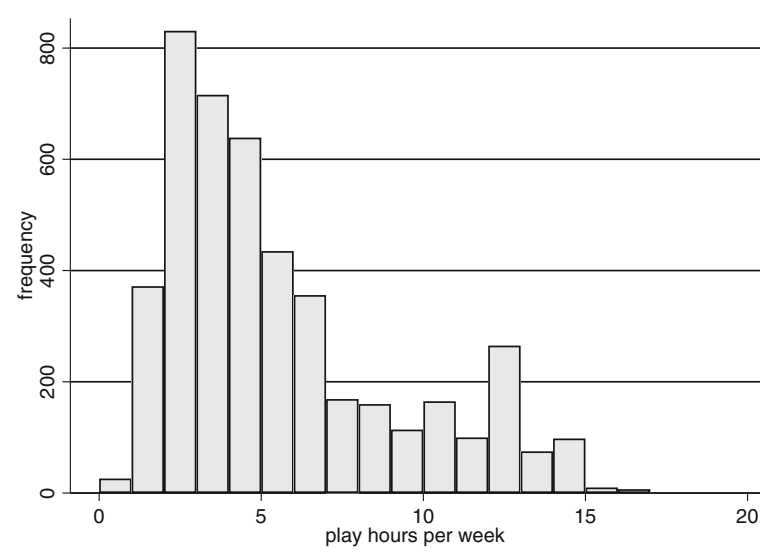

Fig. 1 Histogram of play hours (2006 and 2009 surveys combined)

is the same across the two surveys while the incidence of maternal incidence has risen. These asymmetries will matter if the effects of parental illness are gender-specific. In estimating the effects of parental illness, we will need to control for other negative shocks to the household that might affect child labour: illness among other members of the household, the death of livestock, crop failure, theft, the loss of paid employment and forced eviction. Three-year incidence rates for these shocks are also reported in Table 1. Other control variables in our model include measures of the age and highest school grade previously attained by the child, the child's mother and the child's father; whether the child has a step-mother or step-father; the household's size, wealth level and access to risk-sharing institutions; the sex of the household head and a household power index for the mother; the local community's level of access to healthcare and microfinance services; the incidence of community-level droughts and floods, and whether the community is rural or urban. Definitions and summary statistics for these variables appear in the Appendix; note that the questions in the Young Lives survey relate to serious illnesses only: the results that follow should be interpreted as estimates of the effect of a serious parental illness within the past 3 years on the current allocation of the child's time. ${ }^{7}$

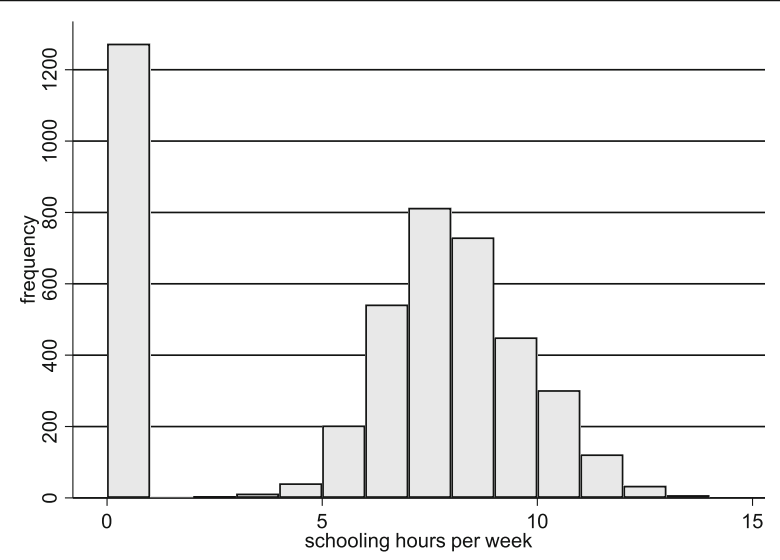

Fig. 2 Histogram of schooling hours (2006 and 2009 surveys combined) 


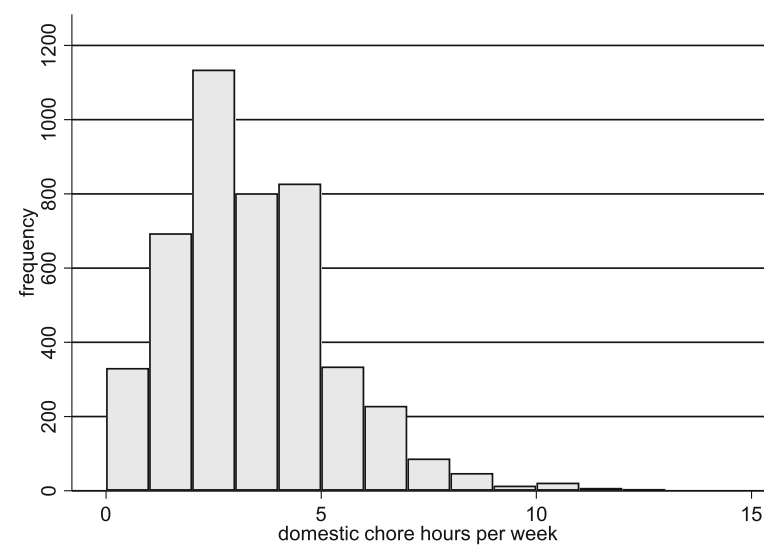

Fig. 3 Histogram of domestic chore hours (2006 and 2009 surveys combined)

\section{Modelling the determinants of child work and child labour}

\subsection{Modelling child work}

We first estimate the effect of parental illness on the number of hours of a child's time that are allocated to the different activities in Table 2. Our estimates are based on a fixed-effects Poisson model with errors clustered at the community level. ${ }^{8}$ For each activity $j$, the dependent variable $\left(y_{i j t}\right)$ is the amount of time that child $i$ records spending on that activity in survey round $t$. This variable is assumed to have a Poisson distribution with a mean equal to:

$$
\mathrm{E}\left(y_{i j t}\right)=\exp \left(\gamma_{1 j} h_{i t}^{m}+\gamma_{2 j} h_{i t}^{f}+x_{i t}^{\prime} \beta_{j}+\eta_{i j}\right)
$$

Here, $h_{i t}^{m}$ and $h_{i t}^{f}$ are indicator variables for the incidence of paternal and maternal illness in the previous 3 years, $x_{i t}$ is a vector comprising the control variables listed above, and $\eta_{i j}$ is a child-specific fixed effect; the $\beta$ and $\gamma$ terms are parameters to be estimated. The model is fitted to the full sample of 2269 children, except in the case of schooling, where we exclude children initially aged 5-6 years because the first year of primary education is for children aged 7-8 years. ${ }^{9}$

Before discussing the estimates of the parameters in Eq. (1), we should comment on the assumption that $h_{i t}^{m}$ and $h_{i t}^{f}$ are exogenous to $y_{i j t}$. There are several different potential sources of endogeneity. Firstly, there could be some household-level characteristics that are associated both with an unhealthy adult lifestyle and with decisions about the allocation of children's time. Secondly, there could be household-level characteristics that are associated both with decisions about fertility (which could influence parental health) and the allocation of children's time. Thirdly, the amount of work a child is doing for her parents could affect their subsequent health. In relation to the first two points, we note that the vector $x_{i t}$ includes a wide range of child- and household-level characteristics, which are listed in the Appendix. For unobserved heterogeneity to affect the consistency of our estimates of the $\gamma$ parameters, this heterogeneity would have to be uncorrelated with the elements of $x_{i t}$; we suggest that there is unlikely to be a large amount of such heterogeneity. Moreover, we have fitted a fixed-effects model, so unobserved heterogeneity that is time-invariant will have no effect on our estimates. In 


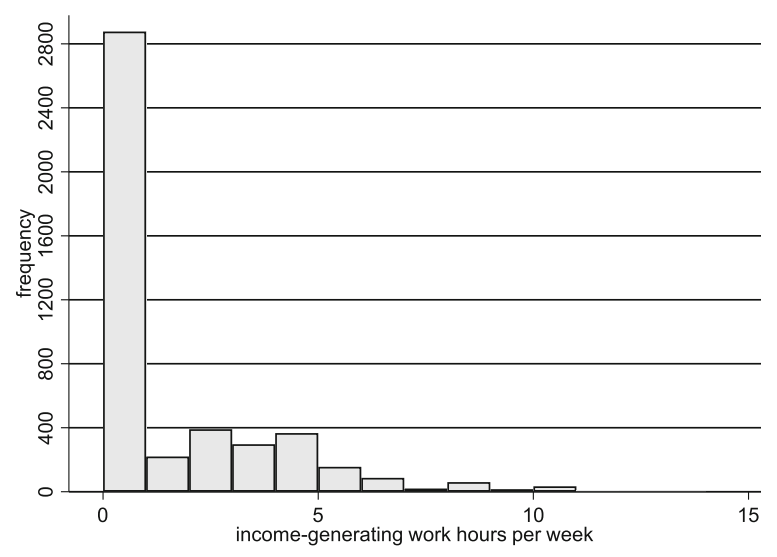

Fig. 4 Histogram of income-generating work hours (2006 and 2009 surveys combined)

relation to the third point, we acknowledge that the ideal approach would be to fit an instrumental variable (IV) model, but there is no obvious IV for parental health in the dataset. Instead, we explore the possibility of reverse causality by fitting a model of $h_{i 2009}^{m}$ and $h_{2009}^{f}$ conditional on $y_{i j 2006}$. Such a model appears in the Appendix: it shows that child time allocation in 2006 has no significant effect on parental health in 2009, and the point estimates of the effects are very close to zero. This gives us some reason to believe that there will not be a large amount of endogeneity bias in our estimates; nevertheless, the absence of an IV should be noted as a caveat in a causal interpretation of the $\gamma$ parameters in Eq. (1). A second caveat in the interpretation of our results is that our self-reported parental illness measures do not include any disaggregation by type of illness or by severity of illness, and the $\gamma$ parameters should be interpreted as mean effects across all types of illness.

Table 2 includes estimates of the $\gamma$ parameters, which can be interpreted as the percentage change in the number of hours worked, on average, in the case of maternal or paternal illness. The table indicates some asymmetries between the effects of maternal and paternal illness. Maternal illness is associated with a $30 \%$ increase in the amount of

Table 2 Determinants of on time spent in different activities

\begin{tabular}{lllll}
\hline & Play & Schooling & Domestic chores & $\begin{array}{l}\text { Income-generating } \\
\text { work }\end{array}$ \\
\hline A. Parental illness & & & & \\
$\quad$ Maternal illness & $-0.098^{* *}(0.025)$ & $-0.033(0.024)$ & $0.299^{* *}(0.025)$ & $-0.170^{*}(0.071)$ \\
Paternal illness & $0.045(0.027)$ & $-0.092^{* *}(0.031)$ & $0.012(0.027)$ & $0.276^{* *}(0.071)$ \\
Observations & 4538 & 1908 & 4514 & 2334 \\
B. Other selected characteristics & & & \\
Illness of another person & $0.004(0.023)$ & $0.004(0.023)$ & $-0.049(0.027)$ & $0.108(0.064)$ \\
Health centre access & $-0.018(0.030)$ & $0.053(0.035)$ & $-0.224^{* *}(0.033)$ & $-0.083(0.106)$ \\
Observations & 4538 & 1908 & 4514 & 2334 \\
\hline
\end{tabular}

Standard errors appear in parentheses. A double asterisk $\left(^{* *}\right)$ beside a parameter indicates that it is significantly different from zero at the $1 \%$ level; a single asterisk $\left(^{*}\right)$ indicates significance at the $5 \%$ level. The parameters indicate the percentage change in the number of hours worked, on average, in the case of maternal or paternal illness, illness of another member of the household, or access to a health centre. The full set of parameters estimates appears in Table 9 of the Appendix 
time spent on domestic chores; correspondingly, there is a $10 \%$ reduction in the amount of time spent in play and a $17 \%$ reduction in the amount of time spent in income-generating work; all of these effects are significant at the 5\% level. The estimated effect of maternal illness on time in school is very small and insignificantly different from zero. Paternal illness is associated with a $28 \%$ increase in the amount of time spent in income-generating work; correspondingly, there is a $9 \%$ reduction in the amount of time spent in school; both of these effects are significant at the $1 \%$ level. The effects on maternal illness on domestic chore time and of paternal illness on income-generating work time are unsurprising, given the traditional gender roles of adults in most Ethiopian households (Haile and Haile 2012). ${ }^{10}$ However, it is more surprising that only paternal illness reduces time in school. One possible explanation is that the extra income-generating work resulting from paternal illness takes up whole days of a child's time, making it impossible to go to school; the extra domestic chores resulting from maternal illness might more easily be fitted around the school day. Previous studies have also found a relatively small effect of parental mortality and morbidity on school hours. In Tanzania, for example, Ainsworth et al. (2005) find that the mortality of one parent (either the mother or the father) has a small and statistically insignificant effect on the number of school hours, while Alam (2015) finds that maternal illness has no significant effect on the probability of a child attending school. In a study of ten Sub-Saharan African countries, Case et al. (2004) find significant effects of the death of one parent on the probability of school attendance, but the fall in probability is typically only about five percentage points. ${ }^{11}$

Estimates of the $\beta$ parameters in Eq. (1) appear in the Appendix, along with a discussion of the effects of all of the control variables. Table 2 also includes parameter estimates for two control variables of particular interest. These show that firstly, the effects of illness of a member of the household other than the mother or father are very small and insignificantly different from zero, and secondly, domestic chore time is reduced by $22 \%$ when the household lives in a location with a local health centre. This effect is significant at the $1 \%$ level, and suggests that extension of access to primary healthcare would be an effective way to mitigate the impact of parental illness on children, as well as reducing the burden of illness on adults.

The Appendix contains further results that focus on the extensive margin of the Table 2 effects, showing the impact of parental illness on the probability that children will be spending any time on domestic chores or income-generating work. It turns out that there are also large effects at the extensive margin: maternal illness raises the probability of involvement in some chores by five percentage points and reduces the probability of involvement in income-generating work by the same amount; paternal illness raises the probability of involvement in income-generating work by four percentage points. Moreover, proximity to a local health centre reduces the probability of involvement in domestic chores by about five percentage points.

It is important to remember that the $\gamma$ parameters measure percentage changes in the time allocated to a particular activity, not the absolute number of hours. Nevertheless, absolute changes can be computed at specific values of the explanatory variables, for example, at their mean values. Across the two rounds of the survey, the mean number of play hours is 5.1 and the mean number of hours of schooling is 5.5; the corresponding figure for domestic chores is 2.9 and the corresponding figure for income- 
generating work is 1.3 . The Table 2 results imply that at these mean values, maternal illness results in a decrease in play time of $5.1 \times 0.098 \approx 0.5 \mathrm{~h}$ per day, a decrease in schooling time of $5.5 \times 0.030 \approx 0.2 \mathrm{~h}$, and a decrease in income-generating work time of $1.3 \times 0.170 \approx 0.2 \mathrm{~h}$; the corresponding increase in chore time is $2.9 \times 0.299 \approx 0.9 \mathrm{~h}^{12}$ The model does not constrain the effects to sum to zero, because the diary does not ask children to account for all $24 \mathrm{~h}$ in a day, but the effects do approximately sum to zero at the mean; this is also true of paternal illness.

The results in Table 2 are based on the assumption that the effects of parental illness and of the control variables are linearly separable. There are two main reasons why this assumption might not hold. Firstly, when only one parent is ill, part of the family's coping strategy might be for the other parent to reduce his or her leisure time, but when both parents are ill, this will not be possible, and the effect on the children will be magnified. We can explore this possibility by adding an interaction term $h_{i t}^{m} \times h_{i t}^{f}$ to the right-hand side of Eq. (1). Secondly, the effects of parental illness on the allocation of a child's time might depend on the characteristics of the child. For example, the effect of illness on the value of the marginal hour allocated to education might depend on the child's existing level of educational attainment, or the effect of illness on the value of the marginal hour allocated to work might depend on the child's age. We can explore this possibility by adding interaction terms in $h_{i t}^{m}$ and educational attainment and in $h_{i t}^{f}$ and educational attainment, or in $h_{i t}^{m}$ and age and in $h_{i t}^{f}$ and age. One challenge in the interpretation of a model with interaction terms is that these terms are necessarily correlated with each other, and the correlations will bias the standard errors upwards. When we fit a model with more than one type of interaction term, almost none of the individual parameters is significantly different from zero. Nevertheless, we can explore the separability assumption by fitting a set of models, each one of which includes a different type of interaction term. The results of such an exercise are reported in Tables 3 and 4 .

Table 3 shows the results of adding $h_{i t}^{m} \times h_{i t}^{f}$ to the model. Here, the interaction term in the play and income-generating work equations is insignificantly different from zero, and the addition of the interaction term makes little difference to the $\gamma$ parameter estimates. However, the coefficient on the interaction term is significantly less than zero in the schooling equation and significantly greater than zero in the domestic chores equation, indicating that when both parents are ill, the effect on the substitution out of schooling and into chores is magnified. The addition of the interaction term makes the

Table 3 The effects of parental illness: models with an interaction term

\begin{tabular}{lllll}
\hline & Play & Schooling & Domestic chores & $\begin{array}{l}\text { Income-generating } \\
\text { work }\end{array}$ \\
\hline Maternal illness & $-0.104^{* *}(0.028)$ & $-0.058(0.033)$ & $0.335^{* *}(0.028)$ & $-0.137(0.071)$ \\
Paternal illness & $0.035(0.034)$ & $-0.155^{* *}(0.049)$ & $0.081^{*}(0.036)$ & $0.317^{* *}(0.086)$ \\
Maternal illness $\times$ paternal illness & $-0.045(0.039)$ & $-0.089^{*}(0.045)$ & $0.275^{* *}(0.038)$ & $0.069(0.096)$ \\
Observations & 4538 & 1908 & 4514 & 2334 \\
\hline
\end{tabular}

Standard errors appear in parentheses. A double asterisk $\left(^{* *}\right)$ beside a parameter indicates that it is significantly different from zero at the $1 \%$ level; a single asterisk $\left.{ }^{*}\right)$ indicates significance at the $5 \%$ level. The parameters indicate the percentage change in the number of hours worked, on average, in the case of maternal or paternal illness 
Table 4 The effects of parental illness: models with interaction terms in child characteristics

\begin{tabular}{|c|c|c|c|c|}
\hline & Play & Schooling & Domestic chores & $\begin{array}{l}\text { Income-generating } \\
\text { work }\end{array}$ \\
\hline \multicolumn{5}{|c|}{ A. Models with interaction terms in the child's age } \\
\hline Maternal illness & $-0.016(0.067)$ & $0.101(0.172)$ & $0.327^{* *}(0.072)$ & $-0.069(0.208)$ \\
\hline Maternal illness $\times$ child age & $-0.009(0.007)$ & $-0.010(0.013)$ & $-0.003(0.006)$ & $-0.010(0.018)$ \\
\hline Paternal illness & $-0.001(0.072)$ & $0.204(0.227)$ & $0.111(0.077)$ & $0.945^{* *}(0.211)$ \\
\hline Paternal illness $\times$ child age & $0.005(0.008)$ & $-0.022(0.017)$ & $-0.010(0.007)$ & $-0.061^{* *}(0.018)$ \\
\hline Observations & 4538 & 1908 & 4514 & 2334 \\
\hline \multicolumn{5}{|c|}{ B. Models with interaction terms in the child's education level } \\
\hline Maternal illness & $-0.081^{* *}(0.030)$ & $-0.055(0.058)$ & $0.297^{* *}(0.034)$ & $-0.179 *(0.092)$ \\
\hline Maternal illness $\times$ child education & $-0.011(0.010)$ & $0.005(0.010)$ & $0.001(0.009)$ & $0.002(0.028)$ \\
\hline Paternal illness & $0.036(0.032)$ & $-0.168^{*}(0.081)$ & $0.046(0.034)$ & $0.418^{* *}(0.090)$ \\
\hline Paternal illness $\times$ child education & $0.008(0.011)$ & $0.018(0.014)$ & $-0.019 *(0.011)$ & $-0.071^{* *}(0.030)$ \\
\hline Observations & 4538 & 1908 & 4514 & 2334 \\
\hline
\end{tabular}

Standard errors appear in parentheses. A double asterisk $\left(^{* *}\right)$ beside a parameter indicates that it is significantly different from zero at the $1 \%$ level; a single asterisk $(*)$ indicates significance at the $5 \%$ level. The parameters indicate the percentage change in the number of hours worked, on average, in the case of maternal or paternal illness

$\gamma$ parameter estimates in the schooling and chores equations larger in absolute value, but these differences are not statistically significant.

Table 4 shows the results of adding interaction terms in educational attainment (measured as the highest school grade attained) or in age. Here, the one large and significant interaction effect is that the impact of paternal illness on time allocated to incomegenerating work is smaller for older children or for more educated children. Age and educational attainment are so highly correlated that it makes little sense to include both interaction terms in a single model, but the most plausible interpretation of the effect is that when a child is closer to completing school, the parents are more reluctant to remove the child from school in order to make up for income lost through paternal illness. There is a qualitatively similar result for the effect of paternal illness on time allocated to domestic chores, but here the effect is much smaller and of marginal statistical significance.

Finally, Table 5 shows estimates of the $\gamma$ parameters when the model (without interaction terms) is fitted to a sample of boys only and a sample of girls only. There are some asymmetries in the effects of parental illness on girls and boys. For boys, the effects of paternal illness are similar to (but somewhat larger than) the aggregate effects

Table $\mathbf{5}$ The effects of parental illness on time spent in different activities (sub-samples)

\begin{tabular}{llllll}
\hline Sub-sample & Effect & Play & Schooling & Domestic chores & $\begin{array}{l}\text { Income-generating } \\
\text { work }\end{array}$ \\
\hline Boys & Maternal illness & $-0.079^{*}(0.035)$ & $-0.049(0.045)$ & $0.263^{* *}(0.042)$ & $-0.084(0.081)$ \\
& Paternal illness & $0.063(0.038)$ & $-0.141^{* *}(0.054)$ & $0.057(0.043)$ & $0.290^{* *}(0.078)$ \\
Girls & Maternal illness & $-0.117^{* *}(0.035)$ & $-0.073(0.043)$ & $0.313^{* *}(0.029)$ & $-0.344^{*}(0.141)$ \\
& Paternal illness & $0.025(0.038)$ & $0.019(0.048)$ & $-0.016(0.033)$ & $0.143(0.160)$ \\
\hline
\end{tabular}

Standard errors appear in parentheses. A double asterisk $\left.{ }^{* *}\right)$ beside a parameter indicates that it is significantly different from zero at the $1 \%$ level; a single asterisk $(*)$ indicates significance at the $5 \%$ level. The parameters indicate the percentage change in the number of hours worked, on average, in the case of maternal or paternal illness 
in Table 2: when his father is ill, a boy can be expected to spend $29 \%$ more time in income-generating work and $14 \%$ less time in school. The estimated effects of paternal illness on girls are all much smaller and insignificantly different from zero. By contrast, the effects of maternal illness are larger for girls than for boys: the increase in girls' domestic chore time is $31 \%$ (versus $26 \%$ for boys) and the reduction in girls' play time is $12 \%$ (versus $8 \%$ for boys). The most marked asymmetry in the effect of maternal illness relates to income-generating work time, which falls by $34 \%$ for girls but only $8 \%$ for boys: there is thus some evidence that whatever income-generating work girls are doing can be sacrificed if the mother needs more help in the home, but this is not the case for boys. ${ }^{13}$ Note that the effects of parental illness on girls' time do not depend on whether she has any brothers, and the effects on boys' time do not depend on whether he has any sisters: when the illness variables are interacted with indicator variables for whether there are no boys in the house (in the case of girls) or no girls in the house (in the case of boys), the coefficients on these interaction terms are insignificantly different from zero $(p>0.1)$. Recall also that children in single-parent households are excluded from the sample, so the estimated effects of maternal (paternal) illness are for households in which the father (mother) is present.

\subsection{Modelling child labour}

The second part of our empirical analysis involves estimation of the determinants of the prevalence of child labour. The harm to individual children from being subjected to child labour will depend on a number of factors, including both the total number of labour hours and the type of work involved. Measuring the extent of harm is a topic for future research, and here we follow previous studies (Baland and Robinson 2000; Basu and Van 1998; Beegle et al. 2006; Ranjan 1999) in focussing on a binary variable $\left(z_{i t}\right)$ which indicates whether child $i$ is subjected to any child labour in survey period $t$. Assume that the data-generating process for $z_{i t}$ takes the form of a fixed-effects Probit model:

$$
\mathrm{P}\left(z_{i t}=1\right)=\Phi\left(\alpha_{1} h_{i t}^{m}+\alpha_{2} h_{i t}^{f}+x_{i t}^{\prime} \phi+\mu_{i}\right)
$$

Here $\Phi($.$) is the cumulative normal density function, \mu_{i}$ is a child-specific fixed effect, and the other variables are as in Eq. (1). Although this model cannot be estimated directly, consistent estimates of the $\alpha$ and $\phi$ parameters can be obtained by replacing $\mu_{i}$ with a linear function of the child-specific mean values of $h_{i t}^{m}, h_{i t}^{f}$ and $x_{i t}$ plus a random effect $\varepsilon(i)$ :

$$
\begin{aligned}
\mathrm{P}\left(z_{i t}=1\right) & =\Phi\left(\alpha_{1} h_{i t}^{m}+\alpha_{2} h_{i t}^{f}+x_{i t}^{\prime} \phi+\pi_{1} \bar{h}_{i}^{m}+\pi_{2} \bar{h}_{i}^{f}+\bar{x}_{i}^{\prime} \omega+\varepsilon(i)\right), \quad \varepsilon(i) \\
& \sim \mathrm{N}\left(\delta, \sigma^{2}\right)
\end{aligned}
$$

This is the correlated random-effects (CRE) model (Wooldridge 2011). For comparison, we also estimate a simple random-effects Probit model in which the $\pi$ and $\omega$ parameters are set to zero.

Table 6 shows the average partial effects of maternal and paternal illness on the probability of child labour, i.e. $\Phi^{\prime}(.) \cdot \alpha_{1}$ and $\Phi^{\prime}(.) \cdot \alpha_{2}$ evaluated at the mean value of $\Phi($.$) ,$ along with the corresponding standard errors. Estimates of the other parameters in the 
Table 6 Average partial effects of illness on the probability of child labour

\begin{tabular}{lll}
\hline & RE Probit Model & CRE Probit Model \\
\hline Maternal illness & $0.132^{* *}(0.014)$ & $0.096^{* *}(0.020)$ \\
Paternal illness & $0.034^{*}(0.017)$ & $0.020(0.023)$ \\
$\sigma$ & $0.114^{* *}(0.043)$ & $0.141^{* *}(0.043)$ \\
Observations & 4538 & 4538 \\
\hline
\end{tabular}

Standard errors appear in parentheses. A double asterisk $\left(^{* *}\right)$ beside a parameter indicates that it is significantly different from zero at the $1 \%$ level; a single asterisk $\left(^{*}\right)$ indicates significance at the $5 \%$ level. The parameters indicate the percentage change in the probability of child labour in the case of maternal or paternal illness

model are available on request. It can be seen that the CRE and simple random-effects estimates are quite similar, although the restrictions implicit in the latter can be rejected at the $1 \%$ level using a $X^{2}$ test. Maternal illness has a relatively large effect on the probability of child labour: in the CRE model, this probability is estimated to increase by about ten percentage points when the mother is ill, an effect that is significant at the $1 \%$ level. The effect of paternal illness is much smaller and in the CRE model is insignificantly different from zero.

The asymmetry in the effects of maternal and paternal illness is somewhat surprising: one might have expected the father's illness to increase child labour through its effect on household income (Basu and Van 1998; Fallon and Tzannatos 1998; Udry 2006). However, it is consistent with the results regarding child time allocation discussed above. Maternal illness mainly affects time spent on domestic chores while paternal illness mainly affects time spent in income-generating work. The percentage increase in domestic chores following maternal illness is approximately equal to the percentage increase in income-generating work following paternal illness (see Table 2), but the average amount of time spent in domestic chores is much higher than the average amount of time spent in income-generating work (see Table 1). Therefore, maternal illness is associated with larger absolute increases in total child work time, and is more likely to take the child's work hours over the threshold that defines child labour.

One possible reason for the relatively large absolute effects of maternal illness is that children's labour is a closer substitute for women's labour than it is for men's, either for cultural reasons or because men's labour often requires upper body strength that children lack, whereas women's labour involves stamina that children do have. In the Appendix, we explore this idea by looking at the effects of illness on household consumption. We show that paternal illness leads to a significant reduction in household expenditure. This suggests that the average household's response to paternal illness is a combination of reduced spending and a moderate increase in the children's income-generating work time: the consumption financed by the marginal hour which a healthy father spends in income-generating work seems not to be essential. However, we also find that maternal illness leads to no significant reduction in household expenditure. The lost maternal labour hours are probably mainly in domestic chores, but the household does not respond by reducing paternal income-generating work time and the consumption it finances: rather, the children must make up for the mother's lost hours.

Table 7 shows average partial effects from the CRE model fitted to girl-only and boyonly sub-samples. It can be seen that the effect of maternal illness on girls is larger than 
Table 7 Average partial effects of illness on the probability of child labour (sub-samples)

\begin{tabular}{|c|c|c|}
\hline & Boys & Girls \\
\hline Maternal illness & $0.050(0.028)$ & $0.132^{* *}(0.029)$ \\
\hline Paternal illness & $0.072^{*}(0.030)$ & $-0.032(0.034)$ \\
\hline
\end{tabular}

that on boys. On average, maternal illness raises the probability of child labour for girls by 13 percentage points (an effect significant at the 1\% level) and the probability of child labour for boys by only five percentage points (an effect not quite significant at the $5 \%$ level). In contrast, paternal illness raises the probability of child labour for boys by seven percentage points (an effect significant at the $5 \%$ level) while having no significant impact on girls. Taken together, the results in Tables 5 and 7 suggest that girls' labour is a very close substitute for women's labour but no substitute for men's labour, while boys' labour is a moderately close substitute for both men's and women's labour. This is consistent with evidence that child labour is a closer substitute for women's labour than it is for men's (Diamond and Fayed 1998; Ray 2000).

\section{Conclusions}

Health shocks are among the most unpredictable and costly causes of economic hardship in developing countries. When a family member is ill, households face loss of income and large, out-of-pocket payments for medical care (Sparrow et al. 2014). This paper contributes to the growing body of evidence that many households cope with such shocks by reallocating the time of family members (Gertler and Gruber 2002; Wagstaff 2007). We show that in at least one country-Ethiopia-parental health shocks have a large effect on the allocation of children's time. ${ }^{14}$

Our results are based on estimates from fixed-effects models applied to longitudinal data from the Ethiopian Young Lives survey. Interpreting our estimates as causal effects (subject to the caveat noted in Section 3.1), we find that paternal illness reduces children's time spent in school and increases their time spent in income-generating work, while maternal illness reduces time spent in play and increases time spent in domestic work. Maternal illness has a relatively large effect on girls while paternal illness has a relatively large effect on boys, which suggests that the allocation of both adult and child time is influenced by traditional gender roles. Moreover, parental illness has significant effects on the prevalence of child labour, i.e. the proportion of children engaged in work detrimental to their personal development. Here the effects of maternal illness are larger than those of paternal illness, which reflects the fact that maternal illness has a relatively large absolute effect on the number of hours that children work.

These results suggest that existing studies may underestimate the size of the association between household welfare and child labour. Measures of welfare are often based on poverty indices related to household income or wealth, and these measures are more strongly correlated with the income-generating work of men than with the domestic work of women in traditional societies. Negative shocks to the supply of labour for domestic work can nevertheless lead to substantial 
reductions in household welfare, and Ethiopian households' coping strategy for such shocks seems to entail effects on children that are at least as large as the effects of lost income-generating capacity through paternal illness. A further implication is that when estimating the return to public investment in adult (and particularly women's) health, it is important to account for the effect of adult health on children's time allocation.

How can the effects of parental illness on child labour be mitigated? Firstly, as shown in Table 2, access to local healthcare services can reduce the impact of parental illness on some types of child work, and in some contexts, the extension of microfinance facilities can help household to insure themselves against illness (Gertler et al. 2009). However, some programmes to extend healthcare have had no significant effect on child labour (Rocha and Soares 2010), and it may be that the effects of maternal illness cannot be fully mitigated unless someone else can be found to do the housework. Some households might be able to rely on extended family members or friends to help out when the mother is ill, but others will have to buy in help; this means that development outcomes for many children will depend crucially on the existence of an efficient market for domestic help.

\section{Endnotes}

${ }^{1}$ In addition, results from studies with data on siblings indicate that family-specific shocks explain a large proportion of the variation in the allocation of children's time. See for example Hull (2017).

${ }^{2}$ These are rounds 2 and 3 of the survey. Round 1 does not include the child time diary that is used to measure our key dependent variables, and round 4 incorporates a cohort who are aged $18-19$, i.e. they are already adults.

${ }^{3}$ About $75 \%$ of children are from food-insecure areas, so there is some concern about the representativeness of the sample. However, when we interact the parental illness variables discussed below with a measure of household wealth, the interaction effects are insignificantly different from zero $(p>0.1)$, and so the over-sampling of poor households is unlikely to affect the relevance of our results to Ethiopia as a whole.

${ }^{4}$ Outes-Leon and Dercon (2008) find that the attrition is purely random.

${ }^{5}$ This trend in the Young Lives data is similar to the trend in the population: see http://data.worldbank.org/indicator/SE.PRM.NENR?locations=ET. Table 1 shows a net increase in the total time devoted to all four activities of $0.4 \mathrm{~h}$ per day. The time diary does not ask children to account for all $24 \mathrm{~h}$ in a day, and there is a residual time category for time spent eating, sleeping and washing. The amount of time allocated to this residual category appears to have diminished.

${ }^{6}$ Evidence from previous studies suggests that self-reported measures of illness are a reliable indicator of the individual's true health status; see for example Butler et al. (1987).

${ }^{7}$ Note also that the effect of permanent illnesses (or illnesses of slowly changing severity) will wash out in the fixed effects. Our estimates relate to the effects of transitions into (or out of) serious illness.

${ }^{8}$ One alternative to this model is a Fixed Effects Negative Binomial model, which does not impose the restriction that the mean of the distribution is equal to the 
variance. However, the restrictions embodied in this model mean that the estimator is unlikely to account properly for individual fixed effects (Guimaraes 2008). Also, when we attempted to fit this model to the data, it failed to converge. Another alternative is a linear model with $\ln (1+y)$ on the left-hand side of the equation. We include estimates of the parameters in such a model in the appendix: they are very similar to the ones reported in the main text.

${ }^{9}$ Note that an observation of zero hours in both survey rounds will be perfectly predicted by the fixed effect, so such observations are excluded from the sample. This means that in most cases the reported sample sizes are somewhat smaller than the total of $2 \times 2269=4538$.

${ }^{10}$ Gendered social norms prevail in much of Ethiopian society, and the responsibilities of men and women are culturally constructed. Activities such as cleaning, cooking and childcare are almost exclusively the responsibility of women and girls, while household repairs, lawn mowing and work outside the home are largely the responsibility of men and boys. However, women do sometimes work outside the home in order to supplement household income: see for example Ogato et al. (2009).

${ }^{11}$ Case et al. (2004) and Mishra et al. (2007) find much larger effects when both parents are dead, but with only a handful of orphans in our sample, it is not possible for us to make a direct comparison using the Ethiopian data. Note that our results are conditional on whether the child is living with its biological mother, and on whether it is living with its biological father, the effects of which are reported in the appendix.

${ }^{12}$ The effect on chore time is larger than in the Tanzanian results reported by Alam (2015), who finds that maternal illness leads to an extra $1.3 \mathrm{~h}$ of chores per week (i.e. about $0.2 \mathrm{~h}$ per day), while paternal illness has no significant effect. Dillon (2012) finds no significant effect in Mali.

${ }^{13}$ However, the standard errors in Table 4 are generally not small enough to establish a statistically significant difference between boys and girls: the only significant difference between the boys' effect and the girls' effect is with regard to paternal illness and schooling.

${ }^{14}$ Even some of the smaller parental health effects that we estimate are of a similar magnitude to the effects of child health reported elsewhere. For example, Alderman et al. (2006) find that in Zimbabwe (where the mean total number of years in school is about 8.5), a one standard deviation increase in the child's height-for-age z-score delays the start of schooling by about 5 months, while Glewwe et al. (2001) find an effect in the Philippines that is about half as large. Expressed as a percentage of the total number of years in school, the effects of a three or four standard deviation difference in height in these studies are of a similar magnitude to the $9 \%$ reduction in school time caused by a paternal health shock in our sample.

${ }^{15}$ One further significant effect is that adult unemployment leads to a reallocation of children's time from play to schooling. The cause of this puzzling effect is a subject for future research.

\section{Appendix}

4.1 Definitions and summary statistics for the additional control variables

Table 8 provides summary statistics for the additional control variables in the model. These variables are defined as follows. 
Table 8 Summary statistics for the additional explanatory variables

\begin{tabular}{|c|c|c|c|c|}
\hline & \multicolumn{2}{|c|}{2006 Survey Round } & \multicolumn{2}{|c|}{2009 Survey Round } \\
\hline & mean & std. dev. & mean & std. dev. \\
\hline \multicolumn{5}{|l|}{ Child characteristics } \\
\hline Child education & 1.35 & 1.92 & 2.77 & 2.80 \\
\hline Child age & 8.24 & 3.34 & 11.16 & 3.34 \\
\hline Female & 0.53 & 0.50 & 0.53 & 0.50 \\
\hline \multicolumn{5}{|l|}{ Parental characteristics } \\
\hline Mother's education & 2.11 & 3.58 & 2.27 & 3.51 \\
\hline Biological mother & 0.86 & 0.35 & 0.81 & 0.39 \\
\hline Mother's age & 34.9 & 8.5 & 37.7 & 8.4 \\
\hline Father's education & 2.77 & 4.16 & 2.95 & 4.10 \\
\hline Biological father & 0.69 & 0.46 & 0.62 & 0.49 \\
\hline Father's age & 43.9 & 10.9 & 46.6 & 10.9 \\
\hline \multicolumn{5}{|l|}{ Household characteristics } \\
\hline Mother's power & 0.46 & 0.28 & 0.46 & 0.28 \\
\hline Male head & 0.78 & 0.41 & 0.77 & 0.42 \\
\hline Household size & 6.25 & 2.06 & 6.25 & 2.05 \\
\hline Wealth index & 0.29 & 0.17 & 0.34 & 0.17 \\
\hline Owns animal & 0.65 & 0.48 & 0.71 & 0.45 \\
\hline Land size & 0.70 & 1.19 & 0.98 & 7.24 \\
\hline Member of social group & 0.74 & 0.44 & 0.73 & 0.44 \\
\hline \multicolumn{5}{|l|}{ Community characteristics } \\
\hline Urban & 0.40 & 0.49 & 0.41 & 0.49 \\
\hline Microfinance & 0.71 & 0.45 & 0.72 & 0.45 \\
\hline Health centre & 0.86 & 0.34 & 0.86 & 0.35 \\
\hline Drought events & 0.40 & 0.49 & 0.40 & 0.49 \\
\hline Flood events & 0.36 & 0.48 & 0.56 & 0.50 \\
\hline Observations & \multicolumn{2}{|c|}{2269} & \multicolumn{2}{|c|}{2269} \\
\hline
\end{tabular}

\section{Child characteristics}

- Child education is the highest school grade completed by the child.

- Child age is the child's age in years

- Female equals one if the child is a girl, and zero otherwise.

\section{Parental characteristics}

- Mother's education is the highest school grade completed by the mother.

- Biological mother equals zero if the child's mother is the biological mother, and zero otherwise.

- Mother's age is the mother's age in years.

- Father's education is the highest school grade completed by the father.

- Biological father equals zero if the child's father is the biological father, and zero otherwise.

- Father's age is the father's age in years. 


\section{Household characteristics}

- Mother's power is an index of the relative influence of the mother in household decision-making.

- Male head equals one if the household head is male, and zero otherwise.

- Household size is the number of people in the household.

- Wealth index is the household wealth index described in Woldehanna et al. (2008).

- Owns animal equals one if the household owns any livestock, and zero otherwise.

- Land size is the surface area of the household's land, in hectares.

- Member of social group equals one if the household is a member of a risk-sharing institution and zero otherwise. These institutions are the iddir, eqqub and debbo. The iddir is a funeral association with contributions that fund expenses when a family member dies; in recent years, iddirs have started making loans or grants to members experiencing other types of shock that entail a loss of income. The eqqub is a rotating credit and saving association which can prioritise payments to members facing financial difficulties. The debbo is an agricultural labour sharing arrangement that can provide extra help to members who are ill (Hoddinott et al. 2012; Krishnan and Sciubba 2009).

\section{Community characteristics}

- Urban equals one if the community in an urban area, and zero otherwise.

- Microfinance equals one if there is a microfinance organisation in the community, and zero otherwise.

- Health centre access equals one if there is a health centre in the community, and zero otherwise.

- Drought events equals one if the community has experienced a drought in the last 3 years, and zero otherwise.

- Flood events equals one if the community has experienced a flood in the last 3 years, and zero otherwise.

\subsection{The full set of parameter estimates in the Table 3 Model}

Table 9 corresponds to Table 3 of the main text but includes the estimated effects of all of the explanatory variables in the model. Among the statistically significant effects, it can be seen that the existing education level of the child (highest grade) is positively associated with current time in school and negatively associated with time spent in income-generating work, while older children spend more time in income-generating work but also more time in play. A child living with its biological mother can be expected to spend less time in domestic chores but more time in income-generating work, while a child living with its biological father can be expected to spend less time in income-generating work and more time in other activities. The mother effect might reflect a preference of mothers to have their biological children working with them in the home, while the father effect suggests that fathers put more weight on the welfare of biological children than on the welfare of step-children. Children of older mothers tend to spend less time in school 
Table 9 Estimated effects of all variables on time spent in different activities

\begin{tabular}{|c|c|c|c|c|}
\hline & Play & Schooling & Domestic chores & $\begin{array}{l}\text { Income-generating } \\
\text { work }\end{array}$ \\
\hline Mother ill & $-0.098^{* *}(0.025)$ & $-0.033(0.025)$ & $0.299 * *(0.025)$ & $-0.170^{*}(0.071)$ \\
\hline Father ill & $0.045(0.027)$ & $-0.091^{* *}(0.032)$ & $0.012(0.027)$ & $0.276^{* *}(0.071)$ \\
\hline Highest grade & $0.019(0.017)$ & $0.039 *(0.021)$ & $0.024(0.018)$ & $-0.098^{* *}(0.034)$ \\
\hline Child age & $0.221 *(0.133)$ & $0.085(0.261)$ & $0.333(0.238)$ & $0.122^{* *}(0.495)$ \\
\hline$(\text { Child age })^{2}$ & $0.017^{* *}(0.001)$ & $-0.011(0.008)$ & $0.000(0.001)$ & $-0.017^{* *}(0.002)$ \\
\hline Mother's education & $-0.040^{*}(0.018)$ & $0.004(0.017)$ & $0.017(0.023)$ & $0.099(0.088)$ \\
\hline Biological mother & $0.027(0.045)$ & $0.115^{* *}(0.042)$ & $-0.405^{* *}(0.037)$ & $0.429^{* *}(0.141)$ \\
\hline Mother's age & $-0.001(0.004)$ & $-0.001(0.005)$ & $-0.003(0.005)$ & $0.005(0.016)$ \\
\hline Father's education & $0.049^{* *}(0.017)$ & $-0.015(0.012)$ & $0.003(0.018)$ & $-0.090(0.064)$ \\
\hline Biological father & $0.144^{* *}(0.035)$ & $0.273^{* *}(0.048)$ & $0.164^{* *}(0.036)$ & $-0.874^{* *}(0.069)$ \\
\hline Father's age & $-0.007^{*}(0.003)$ & $0.001(0.004)$ & $-0.002(0.003)$ & $0.021(0.010)$ \\
\hline Mother's power & $0.367(0.247)$ & $-0.044(0.225)$ & $0.233(0.252)$ & $-1.167^{*}(0.560)$ \\
\hline Male head & $-0.097^{*}(0.046)$ & $-0.139 *(0.058)$ & $-0.049(0.057)$ & $0.477^{* *}(0.144)$ \\
\hline Household size & $-0.012(0.010)$ & $-0.006(0.009)$ & $0.001(0.011)$ & $-0.038(0.028)$ \\
\hline Wealth index & $0.000(0.131)$ & $0.181(0.112)$ & $-0.050(0.149)$ & $-0.603(0.408)$ \\
\hline Owns animal & $0.081 *(0.038)$ & $0.007(0.034)$ & $-0.033(0.037)$ & $0.315(0.205)$ \\
\hline Land size & $0.001(0.001)$ & $-0.001^{* *}(0.000)$ & $0.005^{*}(0.002)$ & $-0.001(0.001)$ \\
\hline Urban & $0.075(0.078)$ & $-0.137(0.087)$ & $-0.002(0.086)$ & $-0.074(0.323)$ \\
\hline Illness of another person & $0.004(0.023)$ & $0.004(0.023)$ & $-0.049(0.027)$ & $0.108(0.064)$ \\
\hline Crop failure & $-0.027(0.026)$ & $-0.023(0.028)$ & $-0.008(0.026)$ & $0.082(0.058)$ \\
\hline Death of livestock & $0.025(0.025)$ & $-0.002(0.026)$ & $-0.042 *(0.025)$ & $-0.001(0.059)$ \\
\hline Theft & $0.018(0.031)$ & $-0.008(0.028)$ & $0.083^{*}(0.032)$ & $0.014(0.078)$ \\
\hline Loss of paid employment & $-0.059^{*}(0.031)$ & $0.082^{* *}(0.026)$ & $-0.023(0.038)$ & $-0.112(0.117)$ \\
\hline Forced eviction & $0.014(0.050)$ & $-0.053(0.050)$ & $-0.059(0.046)$ & $-0.006(0.148)$ \\
\hline Social group & $0.027(0.051)$ & $0.029(0.062)$ & $-0.016(0.046)$ & $-0.022(0.126)$ \\
\hline Microfinance & $-0.053^{* *}(0.055)$ & $0.017(0.048)$ & $-0.167^{* *}(0.051)$ & $0.263^{*}(0.131)$ \\
\hline Drought & $-0.109(0.028)$ & $0.038(0.032)$ & $-0.107^{* *}(0.030)$ & $0.158^{*}(0.080)$ \\
\hline Flood & $0.022(0.026)$ & $0.001(0.027)$ & $-0.037(0.027)$ & $0.009(0.076)$ \\
\hline Health centre access & $-0.018(0.030)$ & $0.053(0.035)$ & $-0.224^{* *}(0.033)$ & $-0.083(0.106)$ \\
\hline
\end{tabular}

Standard errors appear in parentheses. A double asterisk (**) beside a parameter indicates that it is significantly different from zero at the $1 \%$ level; a single asterisk $\left(^{*}\right)$ indicates significance at the $5 \%$ level.

and children of older fathers tend to spend less time in play, while children of households with a male head spend less time in both of these activities and more time in income-generating work, so it appears that younger parents and mothers attach mores weight to the welfare of their children than older parents and fathers. Droughts lead to a reallocation of children's time from domestic work to incomegenerating work, as does the presence of a microfinance facility, which raises concerns about the possible unintended consequences of such facilities. Finally, as noted in the conclusion to the paper, the presence of a health centre reduces the amount of time spent in domestic work, suggesting that access to healthcare services does mitigate the effect of maternal illness; however, the presence of a health centre has no significant effect on the time spent in play, schooling or incomegenerating work. ${ }^{15}$ 


\subsection{Estimating the effects of parental illness in a linear model}

One alternative to the Poisson model in Eq. (1) is a linear model of the following form:

$$
\mathrm{E}\left(\ln \left(1+y_{i j t}\right)\right)=\gamma_{1 j} h_{i t}^{m}+\gamma_{2 j} h_{i t}^{f}+x_{i t}^{\prime} \beta_{j}+\eta_{i j}
$$

The notation here corresponds to the notation in Eq. (1); note that $1+y_{i j t}$ is required on the left-hand side of the equation instead of $y_{i j t}$, because sometimes $y_{i j t}$ $=0$. Table 10, which matches Table 2 in the main text, presents estimates of the $\gamma$ parameters in Eq. (4). The parameters in the two tables cannot be compared directly, because those in Table 2 measure the effect of illness in terms of a percentage change in the number of hours allocated to an activity, while those in Table 10 measure the effect of illness in terms of a percentage change in one plus the number of hours allocated to an activity. Nevertheless, the sign and significance level of each parameter in Table 10 matches that in Table 2; moreover, the parameters are of roughly equal magnitude. This gives us some confidence in the robustness of our results.

\subsection{The extensive margin: determinants of the probability that a child does any work}

Table 11 reports average marginal effects in CRE Probit models of two dependent variables: (i) whether the child spends any time on income-generating work and (ii) whether the child spends any time on household chores. The equations have the following form, analogous to Eq. (3) of the main text:

$$
\begin{aligned}
P\left(y_{i j t}>0\right) & =\Phi\left(\rho_{1} h_{i t}^{m}+\rho_{2} h_{i t}^{f}+x_{i t}^{\prime} \tau+\vartheta_{1} \bar{h}_{i}^{m}+\vartheta_{2} \bar{h}_{i}^{f}+\bar{x}_{i}^{\prime} \theta+u(i)\right) u(i) \\
& \sim N\left(\delta, \quad \sigma^{2}\right)
\end{aligned}
$$

The variables in this equation have the same definition as in Eqs. (1-3). The marginal effects in the table are calculated as $\Phi^{\prime}(.) \cdot \rho_{1}$ and $\Phi^{\prime}(.) \cdot \rho_{2}$ and $\Phi^{\prime}(.) \cdot \tau$, evaluated at the mean value of $\Phi($.$) ; the corresponding standard errors are also$ shown. Maternal illness is estimated to lead to a five percentage point reduction in the probability of any income-generating work and a five percentage point increase in the probability of any household chores; these effects are significant at the $1 \%$ level. Paternal illness is estimated to lead to a four percentage point increase in in the probability of any income-generating work and a three percentage point increase in the probability of any household chores; the latter effect is significant at the $1 \%$ level. Note also that access to a health centre reduces the probability of involvement in household chores by five percentage points, an effect that is

Table 10 The effects of parental illness on time spent in different activities: linear model estimates

\begin{tabular}{lllll}
\hline & Play & Schooling & Domestic chores & Income-generating work \\
\hline Maternal illness & $-0.091^{* *}(0.020)$ & $-0.030(0.037)$ & $0.230^{* *}(0.019)$ & $-0.190^{* *}(0.027)$ \\
Paternal illness & $0.033(0.022)$ & $-0.158^{* *}(0.043)$ & $0.019(0.036)$ & $0.110^{* *}(0.032)$ \\
Observations & 4538 & 1908 & 4514 & 2334 \\
\hline
\end{tabular}

Standard errors appear in parentheses. A double asterisk $\left.{ }^{* *}\right)$ beside a parameter indicates that it is significantly different from zero at the $1 \%$ level; a single asterisk $(*)$ indicates significance at the $5 \%$ level. The parameters indicate the percentage change in one plus the number of hours worked, on average, in the case of maternal or paternal illness 
Table 11 Determinants of the probability that a child does any work

\begin{tabular}{|c|c|c|c|c|}
\hline & \multicolumn{2}{|c|}{ Income-generating work } & \multicolumn{2}{|c|}{ Domestic chores } \\
\hline & a.m.e & s.e. & a.m.e. & s.e. \\
\hline Mother ill & $-0.050^{* *}$ & 0.018 & $0.048^{* *}$ & 0.009 \\
\hline Father ill & 0.042 & 0.022 & $0.033^{* *}$ & 0.011 \\
\hline Child education & $-0.087^{* *}$ & 0.008 & -0.007 & 0.007 \\
\hline Child age & 0.026 & 0.104 & $0.212^{* *}$ & 0.077 \\
\hline Child sex & $0.199^{* *}$ & 0.014 & $-0.036^{* *}$ & 0.008 \\
\hline Mother's education & 0.001 & 0.004 & -0.001 & 0.002 \\
\hline Biological mother & $0.134^{* *}$ & 0.034 & -0.034 & 0.026 \\
\hline Mother's age & -0.002 & 0.003 & -0.001 & 0.002 \\
\hline Father's education & -0.004 & 0.003 & 0.000 & 0.002 \\
\hline Biological father & $-0.176^{* *}$ & 0.025 & $0.047^{* *}$ & 0.018 \\
\hline Father's age & $0.006^{* *}$ & 0.002 & 0.000 & 0.002 \\
\hline Mother's power & -0.065 & 0.045 & 0.008 & 0.025 \\
\hline Male head & $0.138^{* *}$ & 0.040 & -0.015 & 0.026 \\
\hline Household size & -0.003 & 0.008 & 0.003 & 0.005 \\
\hline Wealth index & $-0.244^{* *}$ & 0.104 & -0.103 & 0.067 \\
\hline Owns animal & $0.103^{* *}$ & 0.032 & 0.010 & 0.017 \\
\hline Land size & 0.000 & 0.001 & 0.000 & 0.001 \\
\hline Urban & -0.045 & 0.025 & $-0.042^{*}$ & 0.017 \\
\hline Illness of another person & $0.045^{*}$ & 0.019 & -0.016 & 0.014 \\
\hline Crop failure & 0.013 & 0.019 & -0.018 & 0.019 \\
\hline Death of livestock & $0.035^{*}$ & 0.019 & 0.006 & 0.014 \\
\hline Theft & -0.013 & 0.024 & 0.011 & 0.015 \\
\hline Loss of paid employment & -0.009 & 0.028 & -0.020 & 0.019 \\
\hline Forced eviction & 0.055 & 0.040 & -0.005 & 0.028 \\
\hline Social group & -0.010 & 0.036 & -0.013 & 0.028 \\
\hline Microfinance & 0.012 & 0.027 & 0.010 & 0.021 \\
\hline Drought & $0.042^{*}$ & 0.020 & $0.033^{* *}$ & 0.010 \\
\hline Flood & 0.014 & 0.015 & -0.011 & 0.009 \\
\hline Health centre & -0.012 & 0.020 & $-0.051^{* *}$ & 0.009 \\
\hline I(survey year = 2009) & 0.168 & 0.319 & $-0.471^{* *}$ & 0.092 \\
\hline
\end{tabular}

The columns headed "a.m.e." include average marginal effects, with the corresponding standard errors in the columns headed "s.e." A double asterisk (**) beside a parameter indicates that it is significantly different from zero at the $1 \%$ level; a single asterisk (*) indicates significance at the $5 \%$ level.

significant at the $1 \%$ level. This effect at the extensive margin reinforces the evidence on the link between domestic chores and access to healthcare that is discussed in the main text.

\subsection{Determinants of household expenditure}

In Table 12, we report coefficients from a fixed-effects model of (i) the logarithm of total household food expenditure and (ii) the logarithm of total household non-food expenditure. The explanatory variables are the same as in Table 9, except that the childspecific variables are omitted. Table 12 shows that ceteris paribus, wealthier households, 
Table 12 Estimated effects on household expenditure

\begin{tabular}{|c|c|c|c|c|c|}
\hline & $\begin{array}{l}\text { Food } \\
\text { expenditure }\end{array}$ & $\begin{array}{l}\text { Non-food } \\
\text { expenditure }\end{array}$ & & $\begin{array}{l}\text { Food } \\
\text { expenditure }\end{array}$ & $\begin{array}{l}\text { Non-food } \\
\text { expenditure }\end{array}$ \\
\hline Mother ill & $-0.025(0.023)$ & $0.025(0.038)$ & Urban & $0.169 *(0.076)$ & $0.418^{* *}(0.118)$ \\
\hline Father ill & $-0.049(0.030)$ & $-0.154^{* *}(0.044)$ & $\begin{array}{l}\text { Illness of another } \\
\text { person }\end{array}$ & $0.051^{*}(0.026)$ & $0.040(0.040)$ \\
\hline Mother's education & $-0.023(0.019)$ & $-0.010(0.025)$ & Crop failure & $-0.009(0.026)$ & $-0.088^{*}(0.040)$ \\
\hline Mother's age & $-0.003(0.004)$ & $-0.002(0.006)$ & Death of livestock & $-0.025(0.028)$ & $0.010(0.038)$ \\
\hline $\begin{array}{l}\text { Father's } \\
\text { education }\end{array}$ & $0.017(0.019)$ & $-0.016(0.027)$ & Theft & $0.033(0.034)$ & $0.143^{* *}(0.055)$ \\
\hline Father's age & $0.005^{*}(0.003)$ & $-0.003(0.004)$ & $\begin{array}{l}\text { Loss of paid } \\
\text { employment }\end{array}$ & $-0.041(0.036)$ & $-0.014(0.046)$ \\
\hline Mother's power & $0.225(0.245)$ & $-0.153(0.458)$ & Forced eviction & $0.079 *(0.046)$ & $0.156^{*}(0.072)$ \\
\hline Male head & $0.005(0.055)$ & $0.021(0.077)$ & Social group & $0.035(0.048)$ & $0.049(0.055)$ \\
\hline Household size & $0.047^{* *}(0.010)$ & $0.069^{* *}(0.015)$ & Microfinance & $-0.095^{*}(0.047)$ & $0.038(0.061)$ \\
\hline Wealth index & $0.367^{* *}(0.144)$ & $1.360^{* *}(0.214)$ & Drought & $-0.082^{* *}(0.027)$ & $-0.098^{*}(0.039)$ \\
\hline Owns animal & $0.062^{*}(0.033)$ & $0.011(0.063)$ & Flood & $-0.040(0.024)$ & $0.075^{*}(0.041)$ \\
\hline Land size & $0.001(0.001)$ & $-0.006^{* *}(0.001)$ & Health centre & $0.050^{* *}(0.030)$ & $0.102 *(0.044)$ \\
\hline
\end{tabular}

Standard errors appear in parentheses. A double asterisk $\left(^{* *}\right)$ beside a parameter indicates that it is significantly different from zero at the $1 \%$ level; a single asterisk $\left(^{*}\right)$ indicates significance at the $5 \%$ level.

larger households, urban households and households with access to a health facility have significantly higher levels of both types of expenditure. Theft necessitates higher expenditure on non-food items, the illness of a household member other than the mother or father necessitates higher expenditure on food, and forced eviction necessitates higher expenditure of both types. Access to a microfinance facility is associated with lower food expenditure, which again raises some concerns about the unintended consequences of such facilities. Conditional on these effects, the paternal illness is associated with a $15 \%$ reduction in non-food expenditure, but none of the other parental illness effects is significantly different from zero. Our interpretation of the asymmetry in the expenditure effects of maternal and paternal illness is discussed in Section 3 of the main text.

4.6 Exploring reverse causality: parental health in 2009 and child time allocation in 2006

Table 13 includes estimates from Probit models of parental health in 2009. These models are of the following form:

Table 13 The effect of child time allocation in 2006 on parental health status in 2009

\begin{tabular}{llllll}
\hline & \multicolumn{2}{l}{$\begin{array}{l}\text { Probability that the mother } \\
\text { is ill in 2009 }\end{array}$} & & \multicolumn{2}{l}{$\begin{array}{l}\text { Probability that the father } \\
\text { is ill in 2009 }\end{array}$} \\
\cline { 2 - 3 } & a.m.e. & s.e. & & a.m.e. & s.e. \\
\hline Hours of play per week in 2006 & -0.006 & 0.008 & & -0.002 & 0.005 \\
Hours of schooling per week in 2006 & 0.002 & 0.008 & & -0.006 & 0.007 \\
Hours of domestic chores per week in 2006 & 0.010 & 0.010 & & 0.008 & 0.010 \\
Hours of income-generating work per week in 2006 & -0.011 & 0.007 & & 0.001 & 0.007
\end{tabular}

The columns headed "a.m.e." include average marginal effects, with the corresponding standard errors in the columns headed "s.e" 


$$
P\left(h_{i 2009}^{k}=1\right)=\Phi\left(\sum_{j} \delta_{j} y_{i j 2006}+\lambda h_{i 2006}^{k}+x_{i 2006}^{\prime} \zeta\right)
$$

Here, the parameter $\delta_{j}$ measures the effect of the amount of time that the child spends in activity $j$ in 2006 on the probability that the mother (when $k=f$ ) or father (when $k=m$ ) will be ill in 2009. This effect is estimated conditional on the health status of the parent in 2006 (with a persistence parameter $\lambda$ ) and on the other control variables appearing in Eq. (1) of the main text. Table 13 shows estimates of the marginal effects $\Phi^{\prime} \delta_{j}$ evaluated at the mean values of all explanatory variables; further results are available on request. It can be seen that all of the estimates are very close to (and insignificantly different from) zero. This suggests that the allocation of a child's time has no substantial effect on the subsequent health status of her mother or father, so reverse causality is unlikely to be a serious concern when estimating the parameters in Eq. (1) of the main text.

Acknowledgements

We would like to thank the anonymous referees and the editor for the useful remarks. Responsible editor: Pierre Cahuc.

\section{Competing interests}

The IZA Journal of Labor Economics is committed to the IZA Guiding Principles of Research Integrity. The authors declare that they have observed these principles.

\section{Publisher's Note}

Springer Nature remains neutral with regard to jurisdictional claims in published maps and institutional affiliations.

Received: 18 December 2017 Accepted: 15 March 2018

Published online: 25 April 2018

\section{References}

Ainsworth M, Beegle K, Koda G (2005) The impact of adult mortality and parental deaths on primary schooling in north-western Tanzania. J Dev Stud 41(3):412-439

Alam SA (2015) Parental health shocks, child labour and educational outcomes: evidence from Tanzania. J Health Econ 44:161-175

Alderman H, Hoddinott J, Kinsey B (2006) Long term consequences of early childhood malnutrition. Oxf Econ Pap 58(3):450-474

Baland JM, Robinson JA (2000) Is child labor inefficient? J Polit Econ 108(4):663-679

Basu K, Van PH (1998) The economics of child labor. Am Econ Rev 88(3):412-427

Beegle K, Dehejia RH, Gatti R (2006) Child labor and agricultural shocks. J Dev Econ 81(1):80-96

Bourguignon F, Ferreira FH, Leite PG (2003) Conditional cash transfers, schooling, and child labor: micro-simulating Brazil's bolsa scola program. World Bank Econ Rev 17(2):229-254

Butler J, Burkhauser RV, Mitchell JM, Pincus TP (1987) Measurement error in self-reported health variables. Review of Economics and Statistics 69(4):644-650

Case A, Paxson C, Ableidinger J (2004) Orphans in Africa: parental death, poverty, and school enrollment. Demography 41(3):483-508

Cigno A, Rosati FC (2002) Child labour education and nutrition in rural India. Pac Econ Rev 7(1):65-83

Colmer J (2013) Climate variability, child labour and schooling: evidence on the intensive and extensive margin, (working paper no. 132). Grantham research institute on climate change and the environment. London School of Economics and Political Science, London

Diamond C, Fayed T (1998) Evidence on substitutability of adult and child labour. J Dev Stud 34(3):62-70

Dillon A (2012) Child labour and schooling responses to production and health shocks in northern Mali. J Afr Econ 22(2):276-299

Duryea S, Lam D, Levison D (2007) Effects of economic shocks on children's employment and schooling in Brazil. J Dev Econ 84(1):188-214

Edmonds E (2005) Does child labor decline with improving economic status? J Hum Resour 40(1):77-99

Edmonds E (2006) Child labor and schooling responses to anticipated income in South Africa. J Dev Econ 81(2):386-414

Edmonds E, Pavcnik N (2005) Child labor in the global economy. J Econ Perspect 19(1):199-220

Edmonds E, Schady N (2009) Poverty alleviation and child labor, NBER working paper no.15345. National Bureau of Economic Research, Cambridge

Fallon P, Tzannatos Z (1998) Child labour: issues and directions for the World Bank social protection. Human Development Network, World Bank, Washington

Gertler P, Gruber J (2002) Insuring consumption against illness. Am Econ Rev 92(1):51-70 
Gertler P, Levine DI, Moretti E (2009) Do microfinance programs help families insure consumption against illness? Health Econ 18(3):257-273

Glewwe P, Jacoby HG, King EM (2001) Early childhood nutrition and academic achievement: a longitudinal analysis. J Public Econ 81(3):345-368

Guarcello L, Kovrova I, Rosati FC (2008) Child labour as a response to shocks: evidence from Cambodian villages. In: UCW working paper, understanding Children's work project, Faculity of economics. University of Rome, Rome

Guarcello L, Mealli F, Rosati FC (2010) Household vulnerability and child labor: the effect of shocks, credit rationing, and insurance. J Popul Econ 23(1):169-198

Guimaraes P (2008) The fixed effects negative binomial model revisited. Econ Lett 99(1):63-66

Haile G, Haile B (2012) Child labour and child schooling in rural Ethiopia: nature and trade-off. Educ Econ 20(4):365-385

Heady C (2003) The effect of child labor on learning achievement. World Dev 31(2):385-398

Hoddinott J, Berhane G, Gilligan DO, Kumar N, Taffesse AS (2012) The impact of Ethiopia's productive safety net programme and related transfers on agricultural productivity. J Afr Econ 21(5):761-786

Hull MC (2017) The time-varying role of the family in student time use and achievement. IZA Journal of Labor Economics 6:10

ILO (1973). Minimum age convention (no.138). Retrieved from www.lo.org/dyn/normlex/en/f?p=NORMLEXPUB:12100:0:: NO.P12100 ILO CODE:C138. Accessed 1 Feb 2018

ILO (2008) 18th international conference of labour statisticians (report of the conference). International Labor Organization, Geneva

Jensen P, Nielsen HS (1997) Child labour or school attendance? Evidence from Zambia. J Popul Econ 10(4):407-424

Krishnan P, Sciubba E (2009) Links and architecture in village networks. Economic Journal 119(537):917-949

Mishra V, Arnold F, Otieno F, Cross A, Hong R (2007) Education and nutritional status of orphans and children of HIVinfected parents in Kenya. AIDS Education \& Prevention 19(5):383-395

Moehling CM (2005) "She has suddenly become powerful": youth employment and household decision making in the early twentieth century. J Econ Hist 65(2):414-438

Ogato GS, Boon EK, Subramani J (2009) Gender roles in crop production and management practices: a case study of three rural communities in Ambo district, Ethiopia. J Hum Ecol 27(1):1-20

Outes-Leon I, Dercon S (2008) Survey attrition and attrition bias in young lives. Technical note no.5, young lives, Department of International Development. University of Oxford, Oxford

Ranjan P (1999) An economic analysis of child labor. Econ Lett 64(1):99-105

Ray R (2000) Analysis of child labour in Peru and Pakistan: a comparative study. J Popul Econ 13(1):3-19

Rocha R, Soares RR (2010) Evaluating the impact of community-based health interventions: evidence from Brazil's family health program. Health Econ 19(S1):126-158

Rosati FC, Rossi M (2001) Children's working hours, school enrolment and human capital accumulation: evidence from Pakistan and Nicaragua, UCW working paper, understanding children's work project, Faculity of Economics. University of Rome, Rome

Rosenzweig MR, Evenson R (1977) Fertility, schooling, and the economic contribution of children of rural India: an econometric analysis. Econometrica 45(5):1065-1079

Sparrow R, Poel EV, Hadiwidjaja G, Yumna A, Warda N, Suryahadi A (2014) Coping with the economic consequences of ill health in Indonesia. Health Econ 23(6):719-728

Udry C (2006) Child labor. In: Banerjee AV, Benabou R, Mookherjee D (eds) Understanding Poverty. Oxford University Press, New York, pp 243-258

United Nations (1989). Convention on the rights of the child. Retrieved from www.ohchr.org/en/professionalinterest/ pages/crc.aspx. Accessed 1 Feb 2018

United Nations (2009). Systems of national accounts 2008. Retrieved from http://unstats.un.org/unsd/nationalaccount/ docs/SNA2008.pdf. Accessed 1 Feb 2018

Wagstaff A (2007) The economic consequences of health shocks: evidence from Vietnam. J Health Econ 26(1):82-100 Woldehanna T, Mekonnen A, Alemu T (2008) Young lives: Ethiopia round 2 survey report, Young lives country report, Department of International Development. University of Oxford, Oxford

Wooldridge JM (2011) A simple method for estimating unconditional heterogeneity distributions in correlated random effects models. Econ Lett 113(1):12-15 